\title{
Successful use of cinacalcet to treat parathyroid-related hypercalcemia in two pediatric patients
}

\author{
E Mogas1,2, A Campos-Martorell1,2, M Clemente1,2,3, L Castaño3,4, A Moreno-Galdó2,3,5, D Yeste1,2,3 and \\ A Carrascosa ${ }^{1,2,3}$
}

1Department of Pediatric Endocrinology, Children's University Hospital Vall Hebron, Barcelona, Spain, ${ }^{2}$ Autonomous University of Barcelona, Barcelona, Spain, ${ }^{3}$ Centre for Biomedical Research Network on Rare Diseases (CIBERER), Madrid, Spain, ${ }^{4}$ Endocrinology and Diabetes Research Group, BioCruces Health Research Institute, UPV-EHU, CIBERDEM, Cruces University Hospital, Barakaldo, Spain, and ${ }^{5}$ Department of Pediatrics, Children's University Hospital Vall Hebron, Barcelona, Spain

\author{
Correspondence \\ should be addressed \\ to E Mogas \\ Email \\ emogas48133@gmail.com
}

\section{Summary}

Two pediatric patients with different causes of hyperparathyroidism are reported. First patient is a 13-year-old male with severe hypercalcemia due to left upper parathyroid gland adenoma. After successful surgery, calcium and phosphate levels normalized, but parathormone levels remained elevated. Further studies revealed a second adenoma in the right gland. The second patient is a 13-year-old female with uncommon hypercalcemia symptoms. Presence of pathogenic calcium-sensing receptor gene (CASR) mutation was found, resulting in diagnosis of symptomatic familial hypocalciuric hypercalcemia. Cinacalcet, a calcium-sensing agent that increases the sensitivity of the CASR, was used in both patients with successful results.

\section{Learning points:}

- Hyperparathyroidism is a rare condition in pediatric patients. If not treated, it can cause serious morbidity.

- Genetic tests searching for CASR or MEN1 gene mutations in pediatric patients with primary hyperparathyroidism should be performed.

- Cinacalcet has been effective for treating different causes of hyperparathyroidism in our two pediatric patients.

- Treatment has been well tolerated and no side effects have been detected.

\section{Background}

Hypercalcemia is an uncommon clinical problem in pediatric patients. Etiologies vary with age at diagnosis, and include parathyroid adenoma or hyperplasia, mutations affecting calcium-sensing receptor (CaSR), hypervitaminosis $\mathrm{D}$, inborn errors of metabolism or iatrogenic factors, among others. Hyperparathyroidism, which can be primary or secondary, is caused by an excessive production of parathyroid hormone by the parathyroid gland. Parathyroid adenoma is the most common cause of primary hyperparathyroidism (PHPT). In most cases, it is isolated and the recommended treatment is surgery.

On the other hand, familial hypocalciuric hypercalcemia $(\mathrm{FHH})$ is generally considered a benign disease. It is caused by heterozygous mutation of the CASR gene and most patients are asymptomatic.

Cinacalcet has been successfully used in adults with PHPT. In pediatric patients, it is a drug generally used for 
Table 1 Clinical presentation and diagnosis of the two patients.

\section{Clinical presentation}

Symptoms

Physical examination

Final diagnosis

Time from diagnosis until 4 months after surgery of first adenoma cinacalcet

Patient 1
None
Weight: -2.7 SDS, height: -4 SDS, sable deformity
forearms, left genus valgus. Osteoporosis with bo
reabsorption signs
Left: $12 \times 10 \times 45 \mathrm{~mm}$ parathyroid adenoma; right:
$12 \times 8 \times 4.9 \mathrm{~mm}$ parathyroid adenoma

Left: $12 \times 10 \times 45 \mathrm{~mm}$ parathyroid adenoma; right:

treatment of secondary hyperparathyroidism. However, its use in PHPT is exceptional.

\section{Case 1 presentation}

A 13-year-old male from Senegal underwent a medical examination at his arrival in Spain. There was no personal or familial history of pathology related to hypercalcemia. Physical examination showed weight at $26 \mathrm{~kg}(-2.7$ SDS), height at $130 \mathrm{~cm}$ (-4 SDS) (Table 1) with Tanner stage II, sable deformity in forearms and left genus valgus (Fig. 1). He did not display any clinical symptom. In whole-body skeletal survey, Looser-Milkman lines were observed in both tibias, as well as diffuse osteoporosis with bone reabsorption signs (Figs 2, 3, 4 and 5). A blood test showed hypercalcemia: $13.8 \mathrm{mg} / \mathrm{dL}$ (8.8-10.6), hypophosphatemia: $2.9 \mathrm{mg} / \mathrm{dL} \quad(3-5)$, parathormone (PTH): $1250 \mathrm{pg} / \mathrm{dL}$ (14.5-87.1), alkaline phosphatase: 1587IU/L (50-162) and severe vitamin D deficiency: $7.9 \mathrm{ng} / \mathrm{mL}$ (Table 2).

\section{Case 1 investigation}

The patient was referred to a tertiary pediatric hospital, where further studies were performed. Urine analysis reported elevated calciuria. Severe nephrocalcinosis was revealed in the abdominal ultrasound. Ultrasonography, cervical scan and sestamibi-Tc99m scintigraphy showed a left parathyroid adenoma of $12 \times 10 \times 45 \mathrm{~mm}$. Genetic study of the CASR and MEN1 genes did not show any alteration.

\section{Case 1 treatment}

Prior to surgery, calcidiol was started. The procedure was undergone without incidences or complications. Pathological anatomy confirmed a $2.4 \mathrm{~g}$ weight adenoma without malignancy.
Immediate follow-up showed normal calcium, phosphate and vitamin D levels, but PTH values were persistently elevated $(250 \mathrm{pg} / \mathrm{dL})$. Four months after surgery, cervical MRI and scintigraphy were performed again and a $12 \times 8 \times 4.9 \mathrm{~mm}$ right parathyroid adenoma was found. Images performed at diagnosis of the first adenoma were revised. There was no evidence of previous misdiagnosis.

Given the complex surgical approach and the normality of calcium values, and after obtaining the informed consent and authorization of compassionate

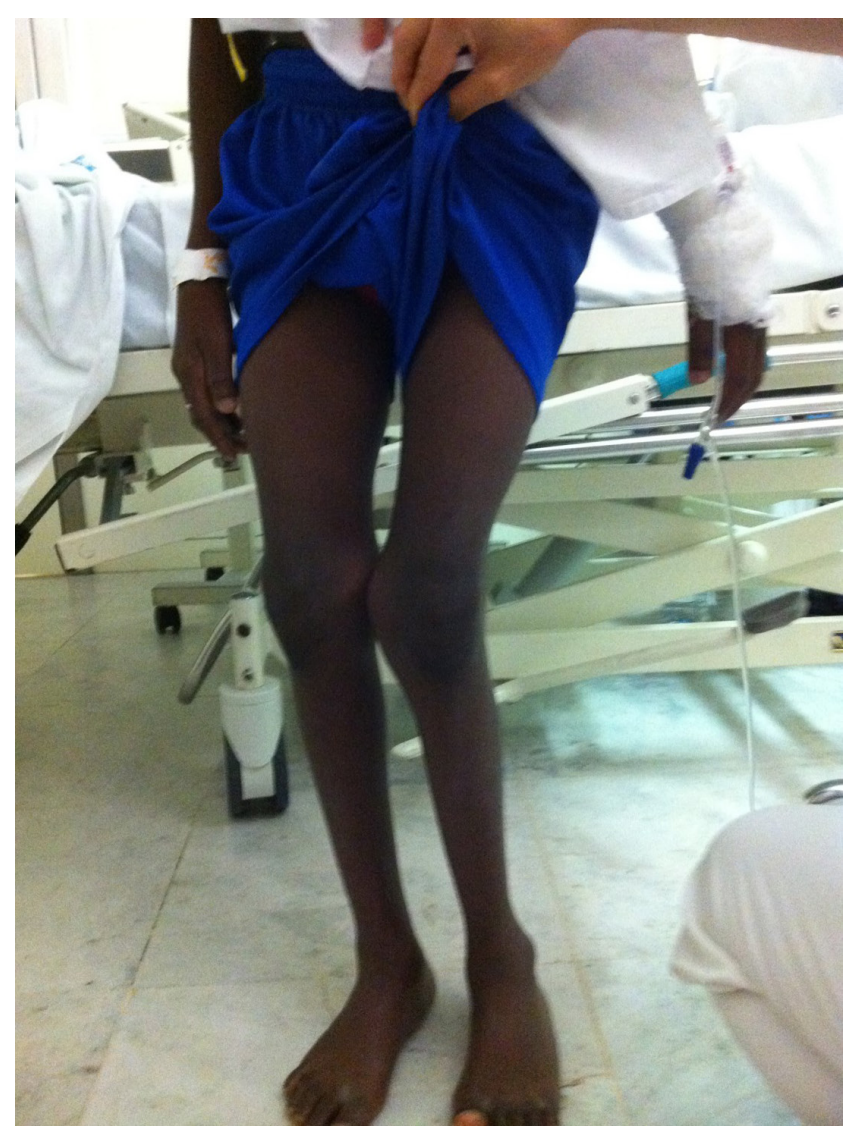

Figure 1

Patient 1 at diagnosis. Important left genus valgus is observed. 

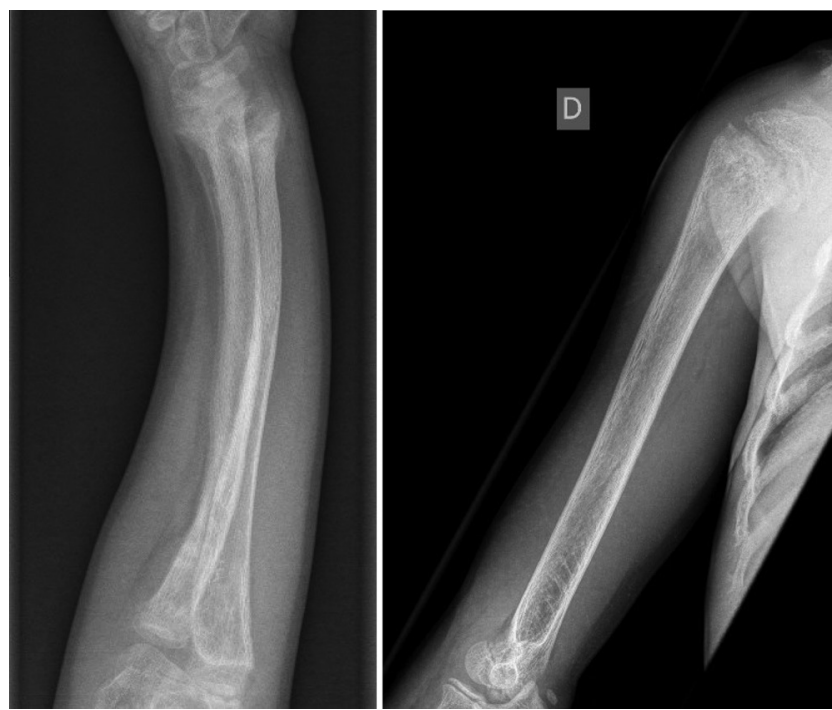

Figure 2

Patient 1 at diagnosis. Sable deformity, and diffuse osteoporosis with bone reabsorption signs is observed. D: right arm

drug use, treatment with $30 \mathrm{mg} / 24 \mathrm{~h}$ cinacalcet was initiated. No acute hypocalcemia or other side effects were reported. Dosage was doubled after 6 months due to the rebound of calcium levels. The patient also underwent epiphysiodesis in left femur and tibia.

\section{Case 1 outcome and follow-up}

Currently, this patient receives $1000 \mathrm{IU} / 24 \mathrm{~h}$ vitamin D and $30 \mathrm{mg} / 12 \mathrm{~h}$ cinacalcet. After 18 -month follow-up, patient remains without symptoms, has gained height (+1.3 SDS) (Fig. 5) and has normal values of calcium, PTH and calciuria (Table 2).

\section{Case 2 presentation}

A 13-year-old female presented with dizziness, muscular weakness and limiting fatigue. She had no significant previous personal or familial history of pathology. Height, weight and BMI were adequate for age with Tanner stage IV; hypercalcemia: $12.4 \mathrm{mg} / \mathrm{dL}$, ionic calcium: $1.49 \mathrm{mmol} / \mathrm{l}$ (1.12-1.32) and hypophosphatemia: $2.8 \mathrm{mg} / \mathrm{dL}$; no other abnormalities in hematology or biochemistry were found. She had no previous calcium determinations.

\section{Case 2 investigation}

Further studies showed PTH: $113 \mathrm{pg} / \mathrm{mL}$, vitamin D: $32 \mathrm{ng} /$ $\mathrm{mL}$ and abnormally normal urinary calciuria (Table 2 ).

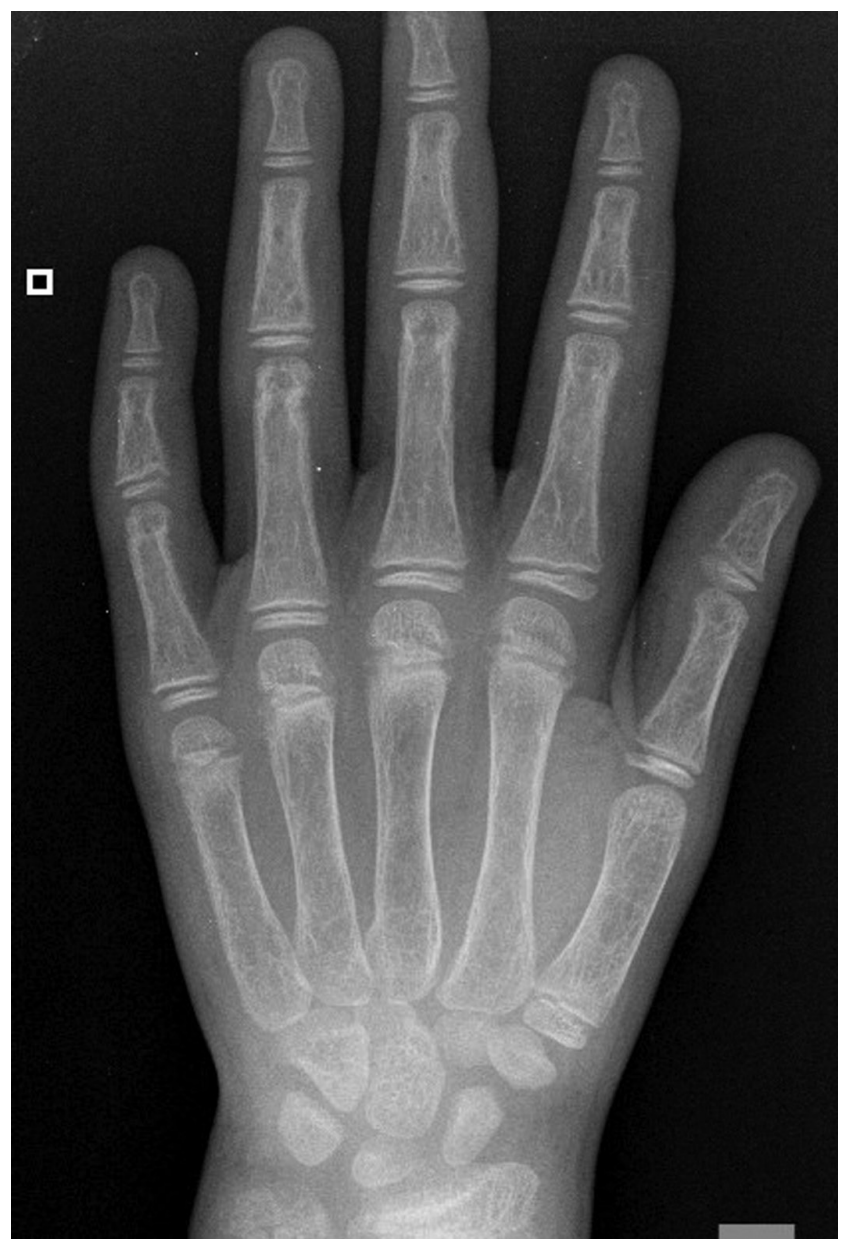

Figure 3

Patient 1 at diagnosis. Diffuse osteoporosis with bone reabsorption signs is observed.

Image studies of the parathyroid gland were normal. Bone densitometry showed $0.934 \mathrm{~g} / \mathrm{cm}^{2}(-0.1$ SDS).

Genetic study of the CASR showed a non-previously described pathogenic mutation of c. $2446 \mathrm{~A}<\mathrm{G}$; $P$. lle816Val. The same mutation was found in the mother, who had no symptoms and serum calcium: $10.6 \mathrm{mg} / \mathrm{dL}$, phosphate: $2.9 \mathrm{mg} / \mathrm{dL}$, calcium/creatinine: $0.7 \mathrm{mg} / \mathrm{mg}$, PTH $31 \mathrm{pg} / \mathrm{mL}$ and vitamin D: $26 \mathrm{ng} / \mathrm{mL}$.

As FHH is usually asymptomatic, pulmonary CT, spirometry, allergy tests, electrocardiogram and cardiac stress test were also performed. No alterations were found.

\section{Case 2 treatment}

After obtaining the informed consent and authorization of compassionate drug use, cinacalcet $30 \mathrm{mg} / 24 \mathrm{~h}$ was initiated. She presented no acute hypocalcemia or other 


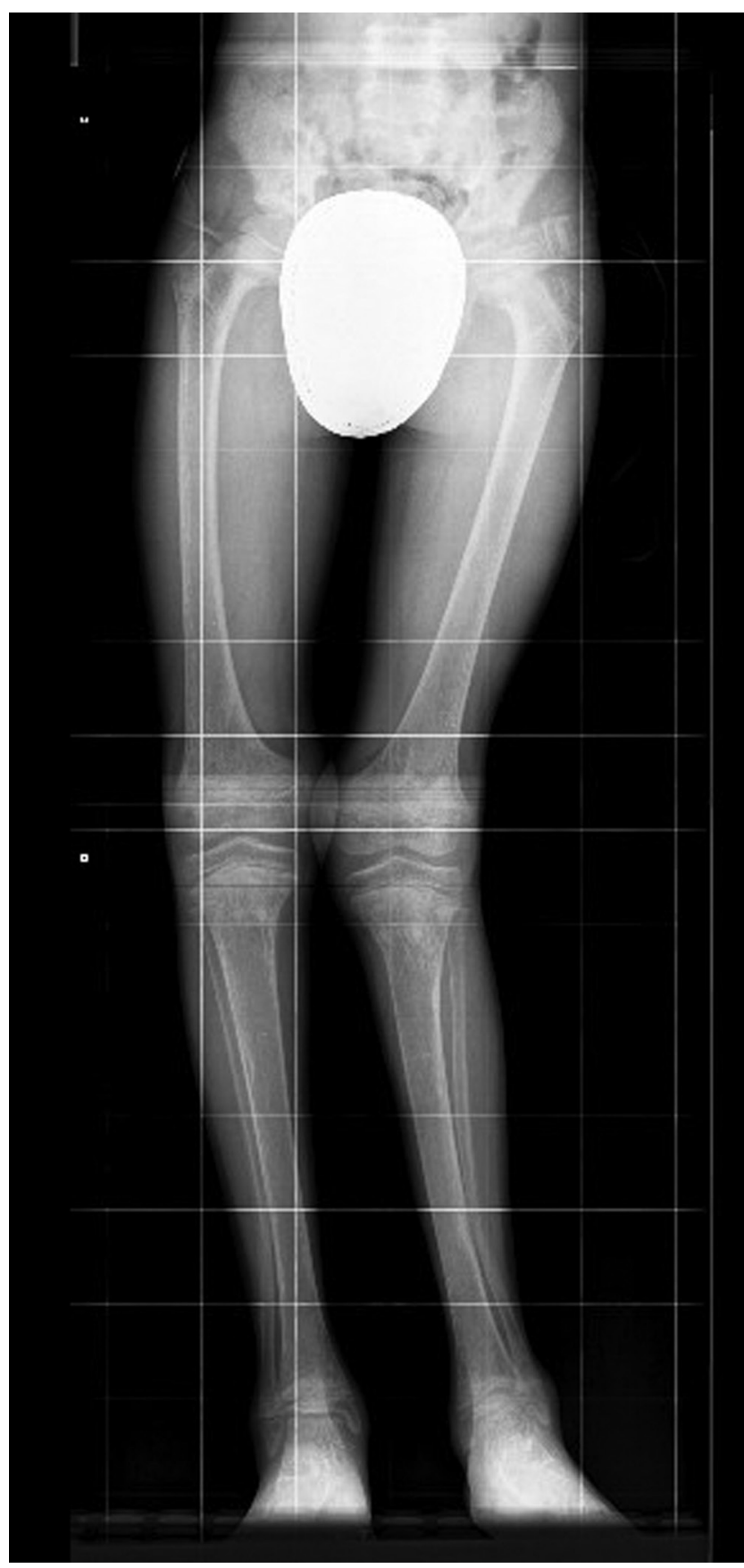

Figure 4

Patient 1 at diagnosis. Diffuse osteoporosis with bone reabsorption signs is observed.

side effects. Calcium, phosphate and PTH levels returned progressively to normal.

\section{Case 2 outcome and follow-up}

After 1 year of treatment, patient had serum calcium: $10.3 \mathrm{mg} / \mathrm{dL}, \quad$ phosphate: $3.8 \mathrm{mg} / \mathrm{dL}, \quad \mathrm{PTH}: \quad 52 \mathrm{pg} / \mathrm{mL}$

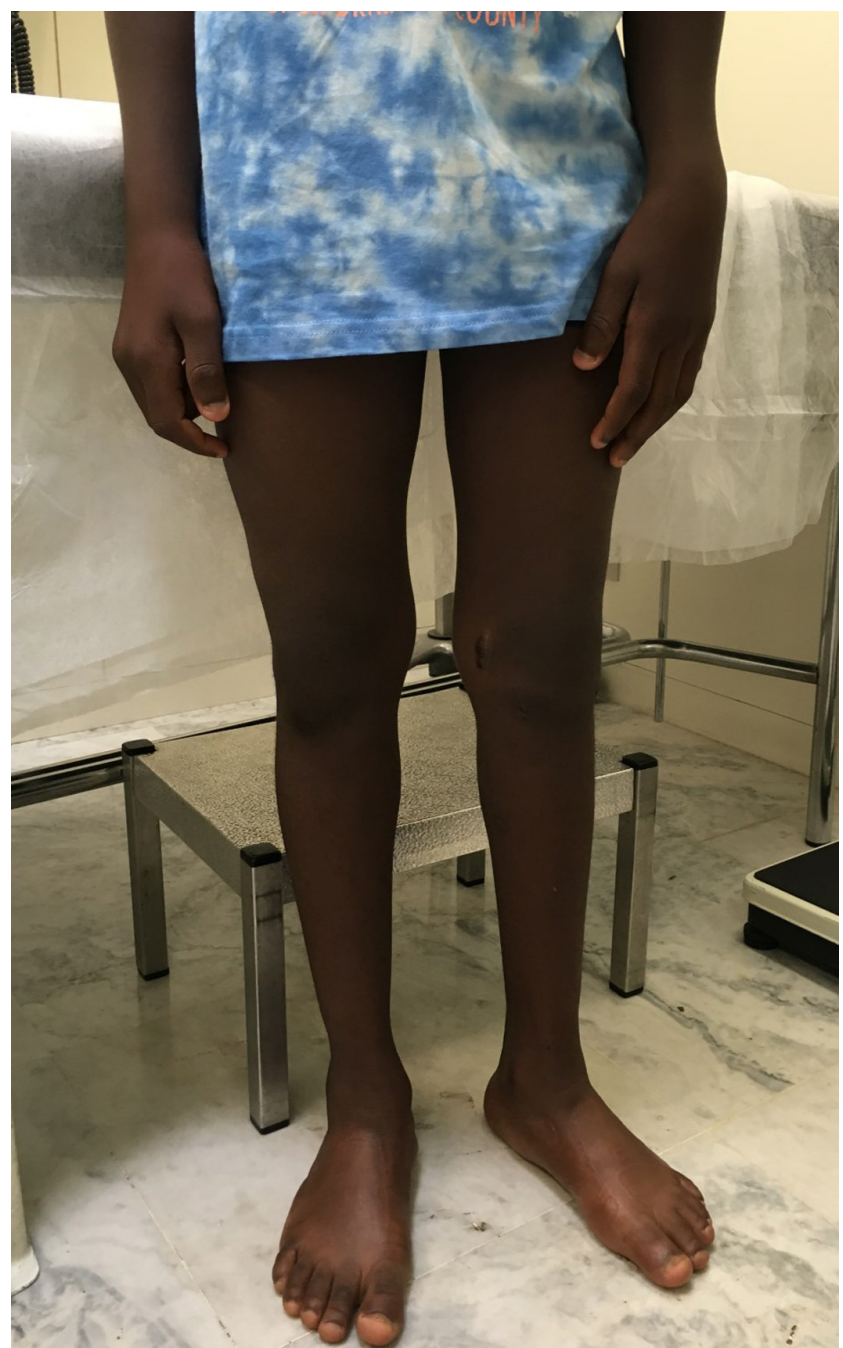

Figure 5

Patient 1 one year after surgery of the parathyroid adenoma, genus valgus and cinacalcet therapy.

and urinary calcium/creatinine: $0.22 \mathrm{mg} / \mathrm{mg} \quad(0.2-0.4)$ (Table 2). She currently reports no dizziness, fatigue or other symptoms.

\section{Discussion}

Cinacalcet is a calcium-mimetic agent capable of increasing the sensitivity of the CASR to extracellular calcium, resulting in reduction of PTH secretion and therefore reducing serum calcium levels (1). Several studies have shown that it is effective for the treatment of secondary hyperparathyroidism (SHPT) and also PHPT in adults $(2,3)$.

In the pediatric population, cinacalcet has been proved useful in avoiding parathyroidectomy and reducing the need of bisphosphonates in severe neonatal 


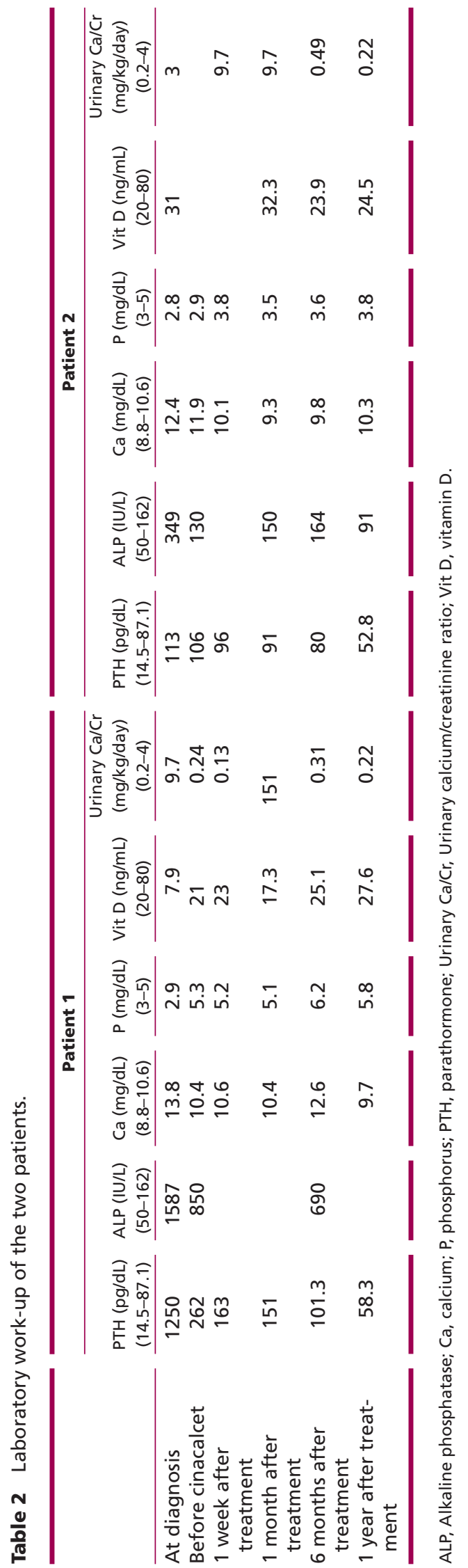

hyperparathyroidism, caused by homozygous mutations with loss-of-function of the CASR gene (4). Ongoing studies are to determine whether its effect also benefits children with SHPT $(5,6)$. However, no significant evidence has yet been published regarding the effects of cinacalcet in the pediatric population, either in PHPT or in cases of $\mathrm{FHH}$.

Regarding the first patient, physical examination at diagnosis showed serious consequences of untreated PHPT. Although he reported no symptoms, bone alterations described were likely to already have caused multiple limitations to growth, development and morbidity.

The main aim of management in children with PHPT is to control hypercalcemia. Surgery is both safe and effective. It is considered the most appropriate treatment for symptomatic parathyroid adenoma $(7,8)$. The choice of operating technique, which includes bilateral neck exploration or minimally invasive parathyroidectomy, depends on the underlying etiology (2). Our patient underwent a minimally invasive procedure without complications.

Recurrent hyperparathyroidism after parathyroidectomy occurs in a low proportion of children and it is mostly associated with familial forms such as MEN syndromes or CASR mutations (9). It is well known that mutations of the suppressive tumor gene Menin are responsible for MEN 1, an autosomal dominant disease that causes predisposition to tumors of the parathyroid glands, anterior pituitary and pancreatic islet cells. Both genetic tests were negative in our first patient.

On the other hand, the CASR gene encodes the calcium-sensing receptor, a G-protein receptor highly expressed in the parathyroid and the kidney. More than 200 different mutations have been described for the CASR (http://www.casrdb.mcgill.ca, searched August 2017). Most of them are inactivating and cause loss-of-function, causing a reduction in the sensitivity to extracellular calcium and consequently an increase in the parathyroid secretion of PTH and a decrease of the calcium renal excretion. This usually results in FHH. A non-previously described mutation of CASR gene c. $2446 \mathrm{~A}<\mathrm{G}$; P. 1le816Val was found in our second patient, which is described as pathogenic by prediction software (Polyphen-2, Mutation Taster).

There was no previous evidence of familial hyperparathyroidism in our patients. Calcium, phosphate and PTH levels were studied in the father of the first patient with normal results. Studying the mother was not an option because she lives abroad. Nevertheless, the mother of the second patient tested positive for the same 
mutation. In these asymptomatic cases of $\mathrm{FHH}$, treatment is not recommended.

However, the second patient had symptomatic hypercalcemia. Although she did not describe nausea, constipation or other digestive disturbances, uncommon symptoms such as muscular weakness, dizziness and fatigue were present.

Finally, cinacalcet therapy was considered in our patients for different reasons: In the first patient, due to the lack of symptoms, normal serum determinations of calcium and phosphate, negative molecular study, recent previous surgery and the anatomical location of the second adenoma. In the second patient, it was the fact that hypercalcemia could not be ruled out as the cause of symptoms presented.

Treatment was started in both patients at initial doses of $30 \mathrm{mg} / 24 \mathrm{~h}$. They did not present acute hypocalcemia, digestive intolerance or any of the most common adverse effects described, such as nausea, headache, arthralgia or myalgia (10). Moreover, treatment has been well tolerated after more than 18 months of follow-up.

In conclusion, this report contributes to illustrate the important effects of PHPT and to expand the knowledge of cinacalcet therapy in the pediatric population. Cinacalcet was safe and well tolerated. Furthermore, it resulted effective in both patients. In the first one, it has avoided new surgery, and the second patient refers improvement of symptomatology. However, the future and long-term evolution of both cases remains uncertain.

\section{Declaration of interest}

The authors declare that there is no conflict of interest that could be perceived as prejudicing the impartiality of the research reported.

\section{Funding}

This report and research did not receive any specific grant from any funding agency in the public, commercial or not-for-profit sector.

\section{Patient consent}

Written informed consent has been obtained from both the patients for the publication of this article and accompanying images.

\section{Author contribution statement}

E Mogas provided care for Patients 1 and 2, researched literature for this manuscript and wrote the manuscript. A Campos-Martorell and M Clemente provided care for Patients 1 and 2. D Yeste, A Moreno-Galdó and A Carrascosa researched literature and reviewed the manuscript.

\section{References}

1 Nemeth EF, Heaton WH, Miller M, Fox J, Balandrin MF, Van Wagenen BC, Colloton M, Karbon W, Scherrer J, Shatzen E, et al. Pharmacodynamics of the type II calcimimetic compound cinacalcet HCl. Journal of Pharmacology and Experimental Therapeutics 2004308 627-635. (https://doi.org/10.1124/jpet.103.057273)

2 Sekercioglu N, Busse JW, Sekercioglu MF, Agarwal A, Shaikh S, Lopes LC, Mustafa RA, Guyatt GH \& Thabane L. Cinacalcet versus standard treatment for chronic kidney disease: a systematic review and meta-analysis. Renal Failure 201638 857-874. (https://doi.org/10 .3109/0886022X.2016.1172468)

3 Khan A, Bilezikian J, Bone H, Gurevich A, Lakatos P, Misiorowski W, Rozhinskaya L, Trotman ML \& Tóth M. Cinacalcet normalizes serum calcium in a double-blind randomized, placebo-controlled study in patients with primary hyperparathyroidism with contraindications to surgery. European Journal of Endocrinology 2015172 527-535. (https://doi.org/10.1530/EJE-14-0877)

4 Gannon AW, Monk HM \& Levine MA. Cinacalcet monotherapy in neonatal severe hyperparathyroidism: a case study and review. Journal of Clinical Endocrinology and Metabolism 2014 99 7-11. (https://doi.org/10.1210/jc.2013-2834)

5 Platt C, Inward C, McGraw M, Dudley J, Tizard J, Burren C \& Saleem MA. Middle-term use of cinacalcet in paediatric dialysis patients. Pediatric Nephrology 201025 143-148. (https://doi. org/10.1007/s00467-009-1294-7)

6 Muscheites J, Wigger M, Drueckler E, Fischer DC, Kundt G \& Haffner D. Cinacalcet for secondary hyperparathyroidism in children with end-stage renal disease. Pediatric Nephrology 200823 1823-1829. (https://doi.org/10.1007/s00467-008-0810-5)

7 Rubin MR, Bilezikian JP, McMahon DJ, Jacobs T, Shane E, Siris E, Udesky J \& Silverberg SJ. The natural history of primary hyperparathyroidism with or without parathyroid surgery after 15 years. Journal of Clinical Endocrinology and Metabolism 200893 3462-3470. (https://doi.org/10.1210/jc.2007-1215)

8 Bilezikian JP, Brandi ML, Eastell R, Silverberg SJ, Udelsman R, Marcocci C \& Potts JT. Guidelines for the management of asymptomatic primary hyperparathyroidism: summary statement from the fourth international workshop. Journal of Clinical Endocrinology and Metabolism 201499 3561-3569. (https://doi. org/10.1210/jc.2014-1413)

9 Kollars J, Zarroug AE, van Heerden J, Lteif A, Stavlo P, Suarez L, Moir C, Ishitani M \& Rodeberg D. Primary hyperparathyroidism in pediatric patients. Pediatrics 2005115 974-980. (https://doi. org/10.1542/peds.2004-0804)

10 Peacock M, Bilezikian JP, Bolognese MA, Borofsky M, Scumpia S Sterling LR, Cheng S \& Shoback D. Cinacalcet $\mathrm{HCl}$ reduces hypercalcemia in primary hyperparathyroidism across a wide spectrum of disease severity. Journal of Clinical Endocrinology and Metabolism 201196 E9-E18. (https://doi.org/10.1210/jc.2010-1221)

Received in final form 2 May 2018

Accepted 10 May 2018 